\title{
The Impacts of Crystalline Structure and Different Surface Functional Groups on Drug Release and the Osseointegration Process of Nanostructured $\mathrm{TiO}_{2}$
}

\author{
Anna Pawlik ${ }^{1}$, Magdalena Jarosz ${ }^{1, *(\mathbb{D})}$, Robert P. Socha ${ }^{2}$ and Grzegorz D. Sulka ${ }^{1}$ (D) \\ 1 Faculty of Chemistry, Jagiellonian University, Gronostajowa 2, 30387 Krakow, Poland; \\ pawlika@chemia.uj.edu.pl (A.P.); sulka@chemia.uj.edu.pl (G.D.S.) \\ 2 Jerzy Haber Institute of Catalysis and Surface Chemistry, Polish Academy of Science, Niezapominajek 8, \\ 30239 Krakow, Poland; ncsocha@cyf-kr.edu.pl \\ * Correspondence: jarosz@chemia.uj.edu.pl; Tel.: +48-126-862-520
}

check for

updates

Citation: Pawlik, A.; Jarosz, M.; Socha, R.P.; Sulka, G.D. The Impacts of Crystalline Structure and Different Surface Functional Groups on Drug Release and the Osseointegration Process of Nanostructured $\mathrm{TiO}_{2}$. Molecules 2021, 26, 1723. https:// doi.org/10.3390/molecules26061723

Academic Editors: Yi Lu and Yongtai Zhang

Received: 11 February 2021

Accepted: 15 March 2021

Published: 19 March 2021

Publisher's Note: MDPI stays neutral with regard to jurisdictional claims in published maps and institutional affiliations.

Copyright: (c) 2021 by the authors. Licensee MDPI, Basel, Switzerland. This article is an open access article distributed under the terms and conditions of the Creative Commons Attribution (CC BY) license (https:/ / creativecommons.org/licenses/by/ $4.0 /)$.

\begin{abstract}
In implantable materials, surface topography and chemistry are the most important in the effective osseointegration and interaction with drug molecules. Therefore, structural and surface modifications of nanostructured titanium dioxide $\left(\mathrm{TiO}_{2}\right)$ layers are reported in the present work. In particular, the modification of annealed $\mathrm{TiO}_{2}$ samples with $-\mathrm{OH}$ groups and silane derivatives, confirmed by X-ray photoelectron spectroscopy, is shown. Moreover, the ibuprofen release process was studied regarding the desorption-desorption-diffusion (DDD) kinetic model. The results proved that the most significant impact on the release profile is annealing, and further surface modifications did not change its kinetics. Additionally, the cell adhesion and proliferation were examined based on the MTS test and immunofluorescent staining. The obtained data showed that the proposed changes in the surface chemistry enhance the samples' hydrophilicity. Moreover, improvements in the adhesion and proliferation of the MG-63 cells were observed.
\end{abstract}

Keywords: titanium dioxide layers; surface modification; silane derivatives; heat treatment; cell response

\section{Introduction}

Modern medicine greatly depends on medical implants applied to support or replace damaged organs or tissues. They are made of one or more biomaterials, which have to be biologically indifferent and non-toxic, and not cause inflammatory reactions or produce harmful substances, but must improve the interaction between the implant surface and surrounding tissues [1]. What is more, their shape and mechanical properties should be suitable for the implantation site [1]. Some of the most commonly used materials for endoprostheses are titanium (Ti) and its alloys because of their excellent mechanical and biological properties and corrosion resistance [1-4]. However, their implantation is associated with a long-term integration process with tissues, leading to side effects such as inflammation and even implant recoil [1,5]. Therefore, it is necessary to modify their surfaces to improve the processes of osseointegration [1,5,6]. A stable and porous layer that firmly adheres to the substrate, such as titanium dioxide obtained by the anodization process, is one such modification $[1,5]$.

Anodic $\mathrm{TiO}_{2}$ (ATO) layers can be further modified to improve the biomaterial interaction with the cells and alter the drug release process. Amorphous $\mathrm{TiO}_{2}$ can be functionalized with sodium hydroxide $(\mathrm{NaOH})$ [7-11], which results in better hydrophilicity of the surfaces, and thus, improvements in the adsorption of water and protein molecules, and consequently, the cell adhesion $[7,12]$. Another way of modifying the samples is coating them with self-assembled monolayers (SAMs), i.e., coatings resulting from the adsorption of organic molecules from a solution [13]. Due to hydroxyl groups (-OH) on the 
$\mathrm{TiO}_{2}$ surface, it is possible to form chemical bonds between them and organic monolayers [13]. Some such compounds are silane derivatives, which possess different functional groups, such as amino $\left(-\mathrm{NH}_{2}\right)$, thiol $(-\mathrm{SH})$, carboxyl $(-\mathrm{COOH})$, and glycidyl $\left(-\mathrm{CH}-(\mathrm{O})-\mathrm{CH}_{2}\right)$ groups [13-15]. Their presence can considerably increase drug delivery control-e.g., take ibuprofen [16] —and improve interactions with cells, e.g., fibroblasts [17]. What is more, their adsorption on the $\mathrm{TiO}_{2}$ surface is almost irreversible [18] and alters the wettability of the samples [19].

To enhance the biomaterial's biocompatibility, we can also modify its surface and crystalline structure. The as-prepared anodic $\mathrm{TiO}_{2}$ layers are amorphous $[1,20,21]$; however, simple annealing of the materials at the appropriate temperature leads to a phase transition to anatase, rutile, or mixed phases [1,20-22]. The thermal treatment of anodic nanostructures also leads to decreased fluorine content, which may play a role in the interaction between the biomaterial and cells $[20,23]$. Among all forms, anatase possesses the best antibacterial properties [24] and may impact drug release from ATO layers [25].

As shown in our previous articles $[11,25,26]$, anodic nanoporous $\mathrm{TiO}_{2}$ layers with different crystalline structures can be used as potential drug delivery systems for compounds with varied structures and water solubility. Typically, the release profiles of, e.g., ibuprofen and gentamicin from amorphous ATO layers, are characterized by a burst release stage, followed by continuous delivery of the medicine $[11,25,26]$. There are many possibilities for suppressing the initial burst effect, among which changing the crystalline structure $[25,26]$ and functionalization of the $\mathrm{TiO}_{2}$ surface [11,27-29] are the most commonly exploited.

Biomaterials have to provide rapid and robust connections with the surrounding tissues to avoid implant rejection [30]. The initial interaction between cells and a biomaterial surface plays a crucial role in cell adhesion, spreading, migration, proliferation, and differentiation [7,31-34]. Within the first seconds in the in vitro or in vivo conditions, the adsorption of water and proteins from the cellular medium or body fluids occurs $[30,35]$. This process is affected by surface properties, such as wettability, surface energy, crystalline structure, electrical properties, and the presence of nano- or microstructures or functional groups $[30,33,36,37]$. The advantage of nanostructured surfaces over the flat titanium sample is due to the increased surface roughness at the nanoscale level, which is combined with locally increased charge density at the surface irregularities, which promotes protein adsorption [36,37]. What is more, the protein adsorption is followed by the interaction between cells and implant surface using the van der Waals forces [4]. Later, bonds between the cell surface receptors (integrins) and extracellular matrix proteins are formed $[4,12,30]$, which further leads to the regulations of the cell functions [12]. Then, the cell's cytoskeleton is reorganized to form filopodia and finger-shaped projections, making it possible to move across the implant surface $[4,30]$. As mentioned above, the functionalization of the $\mathrm{TiO}_{2}$ surface can cause differences in cell behavior on the examined samples. For example, $\mathrm{NaOH}$-modified layers exhibit increased hydrophilicity and surface roughness that should improve the biomaterial cell response, but the release of sodium ions may deteriorate cell adhesion and proliferation [7]. Additionally, the presence of silane derivative monolayers on $\mathrm{TiO}_{2}$ layers affects cell behavior [12,17]. For instance, 3T3 fibroblasts adhere better to the samples modified with (3-aminopropyl)trimethoxysilane than those modified with (3-mercaptopropyl)trimethoxysilane [17].

Although it was proven that the change in the crystalline structure of $\mathrm{TiO}_{2}$ influences the drug delivery process, the cell response to anatase or rutile was inconclusive [38-40]. Some studies confirmed the improvements in the adhesion and proliferation of cells regarding the annealed ATO samples compared with amorphous ones [39], while others demonstrated an adverse effect of fluoride ions regarding cell proliferation [38,40]. Nonetheless, the anatase phase's enhanced impact on the cell response may be attributed to a better wettability of annealed $\mathrm{TiO}_{2}$ layers [40].

Considering the above, the impact of the annealing process on modifying ATO samples with $\mathrm{NaOH}$ was studied. Moreover, the effects of the further functionalization of such layers with different silane derivatives (i.e., (3-aminopropyl)triethoxysilane (APTES), (3- 
glycidyloxypropyl)trimethoxysilane (GPTMS), and (3-mercaptopropyl)trimethoxysilane (MPTMS)) on the ibuprofen delivery process and MG-63 cells response were examined. Complex research on the influences of functionalization of annealed $\mathrm{TiO}_{2}$ layers on the interactions with osteoblast-like cells and drug molecules has not yet been presented to the best of our knowledge.

\section{Results and Discussion}

\subsection{The Effect of the Crystalline Structure on the ATO Modification with $\mathrm{NaOH}$}

The literature shows that annealed titania samples exhibit better bioactivity and interaction with osteoblastic cells $[38,40,41]$. While most articles have been focused mainly on the modification of amorphous ATO samples $[9,10]$, we have decided to examine the influence of the annealing process on the effectiveness of the modification of titanium dioxide layers with $\mathrm{NaOH}$. Based on our previous study [20], two annealing temperatures $\left(400\right.$ and $600{ }^{\circ} \mathrm{C}$ ) were selected for obtaining the anatase and mixed anatase and rutile phases without destruction of the nanoporous structure. For successful modification of $\mathrm{TiO}_{2}$ layers, two approaches were applied-i.e., (i) the samples were annealed prior the immersion in $\mathrm{NaOH}$; (ii) the amorphous $\mathrm{NaOH}$-modified samples were annealed at the temperatures of 400 or $600{ }^{\circ} \mathrm{C}$. The SEM micrographs of the samples modified according to the procedure (i) are shown in Figure 1.

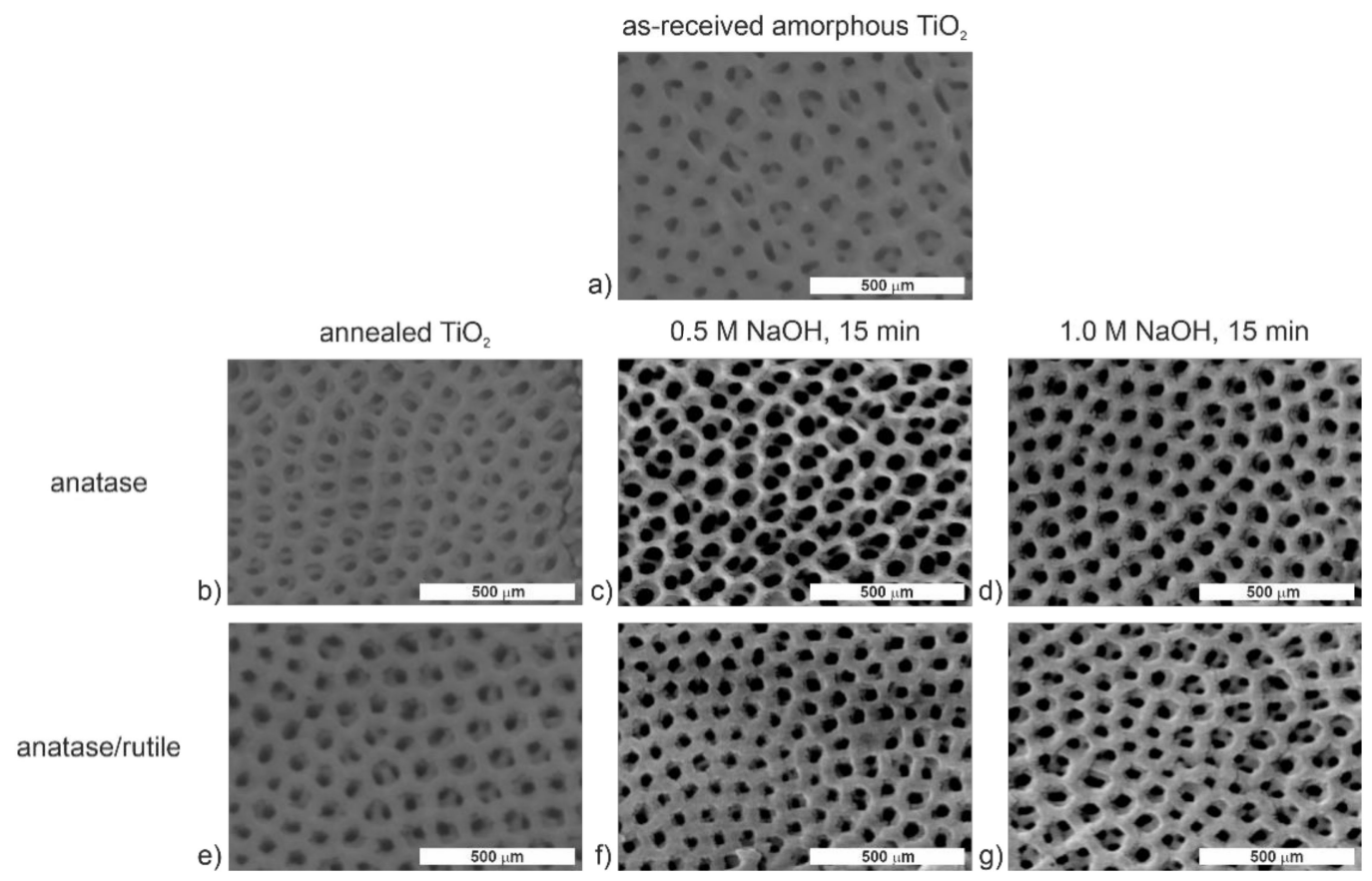

Figure 1. FE-SEM images of nanoporous $\mathrm{TiO}_{2}$ layers non-modified (a,b,e) and modified with $0.5 \mathrm{M}(\mathbf{c}, \mathbf{f})$ or $1.0 \mathrm{M}(\mathbf{d}, \mathbf{g})$ $\mathrm{NaOH}$ for $15 \mathrm{~min}$. The $\mathrm{TiO}_{2}$ layers were non-annealed (a) and annealed at $400(\mathbf{b}-\mathbf{d})$ or $600{ }^{\circ} \mathrm{C}$ (e-g) for $2 \mathrm{~h}$ before the surface modification with $\mathrm{NaOH}$.

Based on FE-SEM images for the annealed $\mathrm{TiO}_{2}$ layers (Figure 1), it can be stated that, contrary to the amorphous anodic $\mathrm{TiO}_{2}$ [11], soaking in $\mathrm{NaOH}$ solution did not lead to any significant change in the surface morphology. Moreover, even when a more concentrated sodium hydroxide solution (Figure 1d,g) was used, the surface morphology did not change like it did for the amorphous layers [11]. Figure S1 and Table S1 show the chemical composition of studied $\mathrm{TiO}_{2}$ layers based on the EDS analyses. In general, the EDS spectra of ATO layers showed only $\mathrm{Ti}$ and $\mathrm{O}$ peaks, and the calculated amounts of sodium and fluorine were both equal to 0 within the margin of error. It indicates that the annealed $\mathrm{TiO}_{2}$ samples cannot be modified effectively with sodium hydroxide using the 
proposed experimental procedure, which is in contradiction to the research conducted by Morgado et al. [42], where titanate nanotubes were formed by hydrothermal treatment of an anatase powder with a concentrated $\mathrm{NaOH}$ solution $(10 \mathrm{M})$ at moderate temperatures $\left(90-170{ }^{\circ} \mathrm{C}\right)$. Therefore, it can be concluded that the surface modification of annealed $\mathrm{TiO}_{2}$ layers can be effective only at higher $\mathrm{NaOH}$ concentrations and temperatures, and extended modification times. However, as we have previously demonstrated, the $\mathrm{NaOH}$ concentration increase may result in the deterioration of $\mathrm{TiO}_{2}$ nanoporosity [11], which is a disadvantage. Therefore, the modification sequence was changed so that the annealing process was conducted after the modification with $\mathrm{NaOH}$. FE-SEM images of the obtained nanostructures are presented in Figure 2.

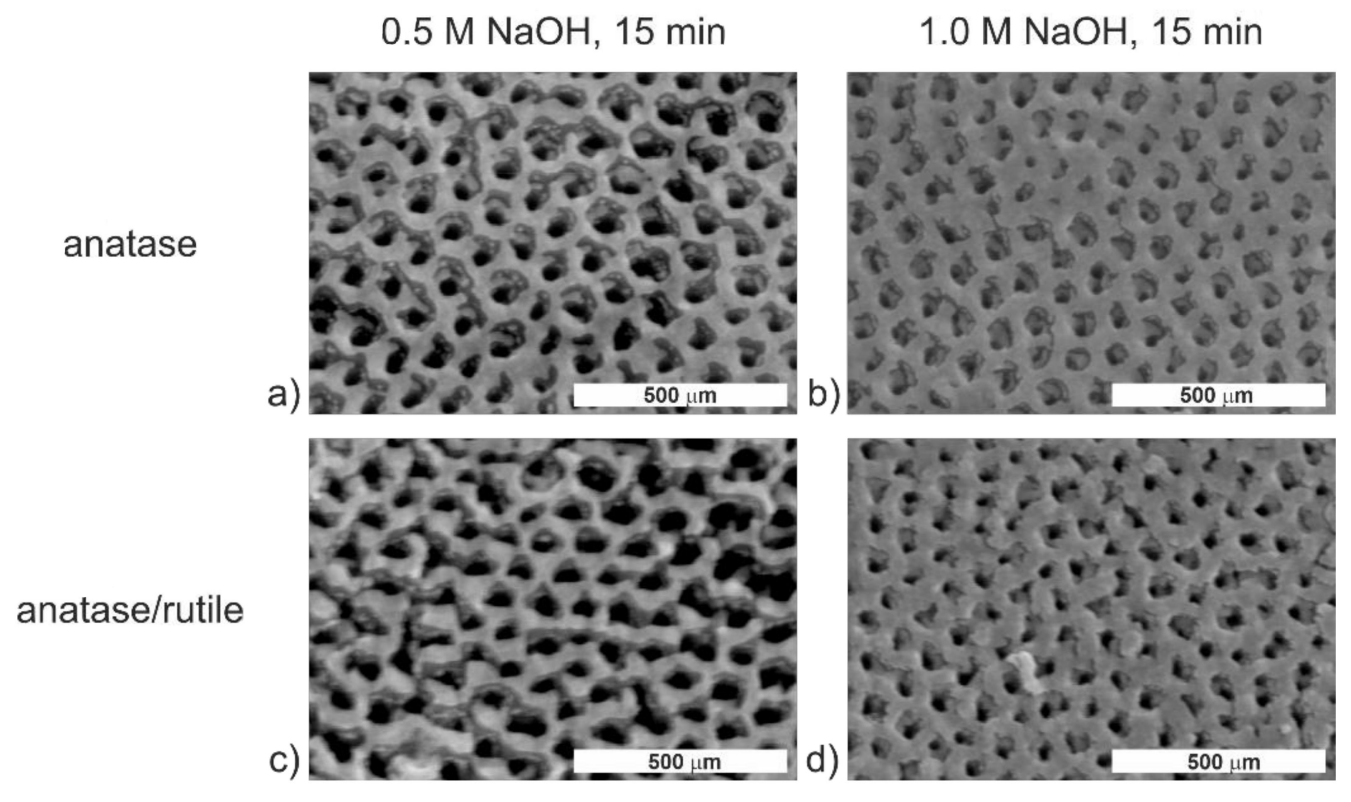

Figure 2. Microphotographs from the FE-SEM of ATO layers modified with $0.5 \mathrm{M}(\mathbf{a}, \mathbf{c})$ or $1.0 \mathrm{M}(\mathbf{b}, \mathbf{d}) \mathrm{NaOH}$ for $15 \mathrm{~min}$. The $\mathrm{TiO}_{2}$ layers were annealed at $400(\mathbf{a}, \mathbf{b})$ or $600^{\circ} \mathrm{C}(\mathbf{c}, \mathbf{d})$ for $2 \mathrm{~h}$ after the modification with $\mathrm{NaOH}$.

FE-SEM micrographs for such modified $\mathrm{TiO}_{2}$ layers show slight differences in the surface morphology compared to the non-modified substrates (Figure 1a). Their surfaces look more roughened than as-prepared ATO layers, though the nanoporous structure of ATO is not destroyed under any of the applied conditions. The performed EDS analyses revealed that, apart from $\mathrm{Ti}$ and $\mathrm{O}$ peaks, the Na peak was present in the spectra (Figure S2). Besides, the $\mathrm{Na}$ content was at the same level for both the non-annealed and annealed samples [11]. As in the previous case, fluorine was absent in the studied substrates (Table S2). The above results confirm that the proposed procedure of modification is effective. Considering the previous studies [25,26], which demonstrated improved drug release kinetics from the anatase samples, $\mathrm{TiO}_{2}$ layers modified with $0.5 \mathrm{M} \mathrm{NaOH}$ for $15 \mathrm{~min}$ and annealed at $400{ }^{\circ} \mathrm{C}$ for $2 \mathrm{~h}$ (called Nan) were used for further studies.

\subsection{Surface Modifications of Annealed $\mathrm{TiO}_{2}$ Layers with Silane Derivatives}

As mentioned, various functional groups on the surface affect ATO layers' interactions with drug molecules and cells [16,17]. Therefore, the Nan samples were further modified with silane derivatives, namely, APTES, GPTMS, and MPTMS. Based on our previous study [11] on the modification of amorphous ATO layers with silane derivatives, we applied the same procedure for the annealed $\mathrm{NaOH}$-modified ATO samples. Briefly, samples were immersed in a 1\% APTES, GPTMS, or MPTMS solution for $2 \mathrm{~h}$. Absolute ethanol was used as a solvent because even a small amount of water may convert silane derivatives into silanes. Moreover, computer simulations showed that the adsorption of 
water molecules on the $\mathrm{TiO}_{2}$ surface could be competitive with the adsorption of organic molecules [39].

The silane derivatives are small molecules, and the immersion time is short, so it can be expected that the samples would be coated with monolayers. Due to this fact, the elemental composition of ATO surfaces was characterized by using X-ray photoelectron spectroscopy, and the results are shown in Figure 3 and collected in Table 1.

MNan

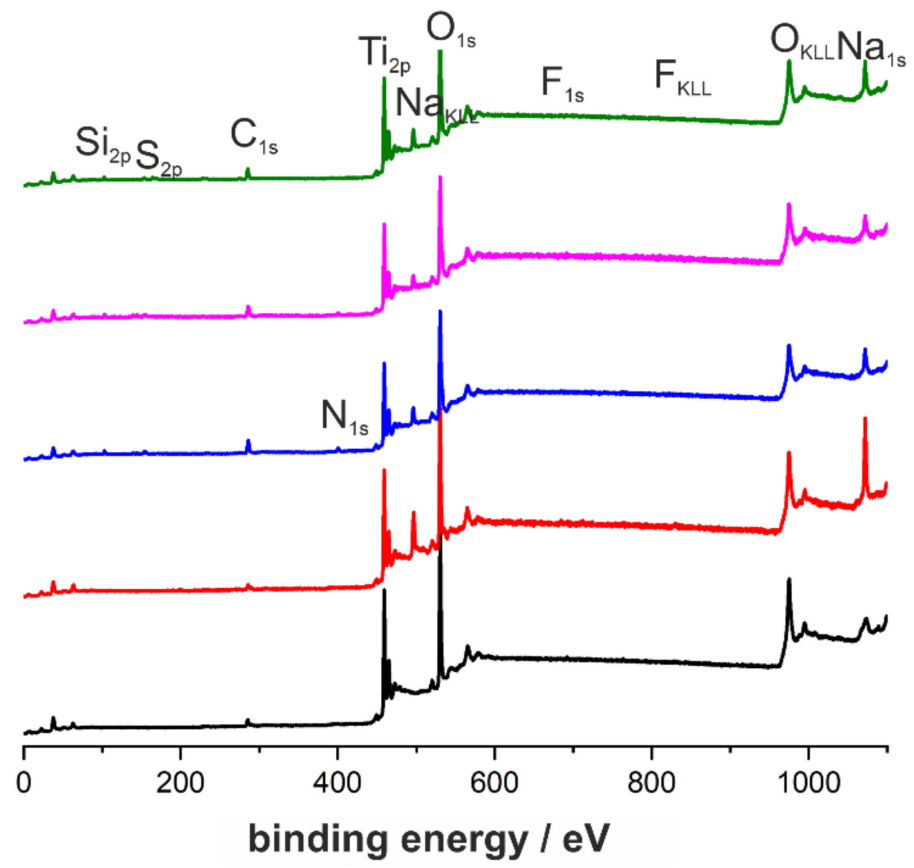

Figure 3. XPS (X-Ray Photoelectron Spectroscopy) survey spectra of the non-modified (an) and modified (Nan, Anan, GNan, and $\mathrm{MNan}$ ) $\mathrm{TiO}_{2}$ samples.

Table 1. Elemental compositions of non-modified (an) and modified (Nan, Anan, GNan, and MNan) $\mathrm{TiO}_{2}$ samples based on the XPS analyses.

\begin{tabular}{ccccccccc}
\hline \multirow{2}{*}{ Sample } & \multicolumn{7}{c}{ Atomic Content [\%] } \\
\cline { 2 - 9 } & $\mathbf{C}$ & $\mathbf{O}$ & $\mathbf{T i}$ & $\mathbf{F}$ & $\mathbf{N a}$ & $\mathbf{S i}$ & $\mathbf{N}$ & $\mathbf{S}$ \\
\hline an & 11.14 & 63.70 & 24.61 & 0.55 & - & - & - & - \\
Nan & 9.12 & 59.28 & 19.05 & 0.72 & 11.84 & - & - & - \\
ANan & 19.72 & 50.75 & 15.85 & 0.00 & 4.32 & 6.29 & 3.07 & - \\
GNan & 19.03 & 54.49 & 16.94 & 0.18 & 3.89 & 5.47 & - & - \\
MNan & 14.57 & 55.07 & 17.68 & 0.44 & 4.62 & 4.08 & - & 3.53 \\
\hline
\end{tabular}

Since XPS is a technique used to analyze the surface chemistry of materials, the differences in the atomic contents of characteristic elements for the tested samples were observed. As expected, the fluorine content was low for annealed samples because the heat treatment resulted in removing those anions from the ATO layers. For the non-modified and $\mathrm{NaOH}$-modified ATO layers, carbon's presence can be attributed to adventitious carbon contamination or carbon species embedded in the ATO structure, e.g., during the anodization process. In contrast, for the silane-modified samples, higher $\mathrm{C}$ content was strictly related to the modification process. The effectiveness of surface modification was confirmed by silicon peaks (Figure 3) in all XPS spectra for silane derivative-modified samples. It is worth noting that the sodium content decreased considerably after the modification with silane derivatives (Table 1), which confirms that the surface of titanium dioxide was covered with other molecules. Additionally, for more in-depth chemical analysis of the modified $\mathrm{TiO}_{2}$ layers, the detailed XPS spectra for nitrogen, sulfur, silicon, oxygen, and 
carbon are presented in Figures S3-S7, Supplementary Information. Additionally, explanations of the particular signals in each core-level XPS spectra are given there, confirming the successful modification of ATO substrates with silane derivatives.

One of the factors that significantly affect cell adhesion is the wettability of the biomaterials $[30,35,43]$ due to the adhesion of water and proteins $[4,12]$. Their adsorption occurs immediately after the implant is placed in the patient's body, so the biomaterial surface should be hydrophilic $[4,12,35,43]$. For this reason, the wettability of modified ATO samples was determined. The average values of the contact angle with the standard deviation of the mean for $n=20$ are presented in Table 2 .

Table 2. Contact angle measurements of the non-modified (an) and modified (Nan, Anan, GNan, and MNan) $\mathrm{TiO}_{2}$ samples.

\begin{tabular}{cc}
\hline Sample & Contact Angle [ ${ }^{\circ}{ }^{\text {] }}$ \\
\hline an & $41.1 \pm 3.3$ \\
Nan & $14.3 \pm 2.2$ \\
ANan & $20.3 \pm 2.7$ \\
GNan & $18.6 \pm 3.9$ \\
MNan & $29.1 \pm 3.0$ \\
\hline
\end{tabular}

As shown in Table 2, contact angle values were significantly less than $90^{\circ}$, proving the hydrophilic character of the samples. All the annealed substrates were more hydrophilic than as-prepared amorphous $\mathrm{TiO}_{2}$ layers [11], which is consistent with the literature data $[4,44]$. Such behavior may be explained in terms of the increased nano- and microroughness of the annealed surface and the presence of the anatase phase itself [44]. It should also be pointed out that the hydrophilicity of nanostructured $\mathrm{TiO}_{2}$ also depends on time (the so-called aging process) [44], storage conditions (e.g., access to air and temperature) [45], and anodization conditions (e.g., applied voltage, electrolyte composition, and substrate used) [46]. In the case of the samples used in the present work, only freshly prepared samples were applied for all the experiments. However, from our laboratory experience, we observed that annealed and aged samples (even after one year of storage at room temperature) remained hydrophilic (contact angles were in the range of $40-50^{\circ}$ ). This is also consistent with the work of Shin et al. [44], who showed that for annealed titania nanotubes formed on the pure Ti foil, the contact angle increased by $15^{\circ}$ after three months of the storage.

Further surface modifications led to the enhancement of hydrophilic properties. Among them, $\mathrm{NaOH}$-modified layers were the most hydrophilic $(14.3 \pm 2.2)$. The different wettability levels of the examined samples were caused by their chemical surface properties caused by various functional groups. The improvement of the $\mathrm{TiO}_{2}$ surface's wettability after their immersion in $\mathrm{NaOH}$ may be correlated with the presence of hydroxyl groups. The functionalization with silane derivatives slightly increases the contact angle, when compared with $\mathrm{NaOH}$-modified samples $(29.1 \pm 3.0,20.3 \pm 2.7$, and $18.6 \pm 3.9$, for MPTMS, APTES, and GPTMS, respectively). It is consistent with the observations from Lin et al. [17], suggesting that the ATO layers with thiol groups at the surface were more hydrophobic than those with amino groups. Based on the above results, it can be concluded that all examined samples may exhibit good adsorption of proteins from the medium, and consequently, sufficient cell adhesion can be expected.

\subsection{Effects of the Surface Modification on Ibuprofen Release Kinetics}

As presented in our previous studies $[11,25,26]$, drugs with different structures and water-solubility can be released from $\mathrm{TiO}_{2}$ nanopores. Such a drug delivery process is described with the desorption-desorption-diffusion (DDD) kinetic model proposed and described by Jarosz et al. [25]. The DDD model involves the desorption of the drug molecules from the $\mathrm{TiO}_{2}$ surface, followed by the desorption and diffusion of the molecules from the nanoporous structure [25]. This model may be applied for both single [25] and 
double-drug release kinetics [26], as well as for the release process from ATO layers with different crystalline structures [25,26] and surface modification [11].

Figure 4 presents the ibuprofen release profiles according to the DDD kinetic model. The characteristic parameters describing the process are collected in Table S3. Additionally, the amounts of ibuprofen released at predetermined time points from the samples are shown in Table S4, and the cumulative masses of the drug released after $168 \mathrm{~h}$ from the samples are reported in Table S5.
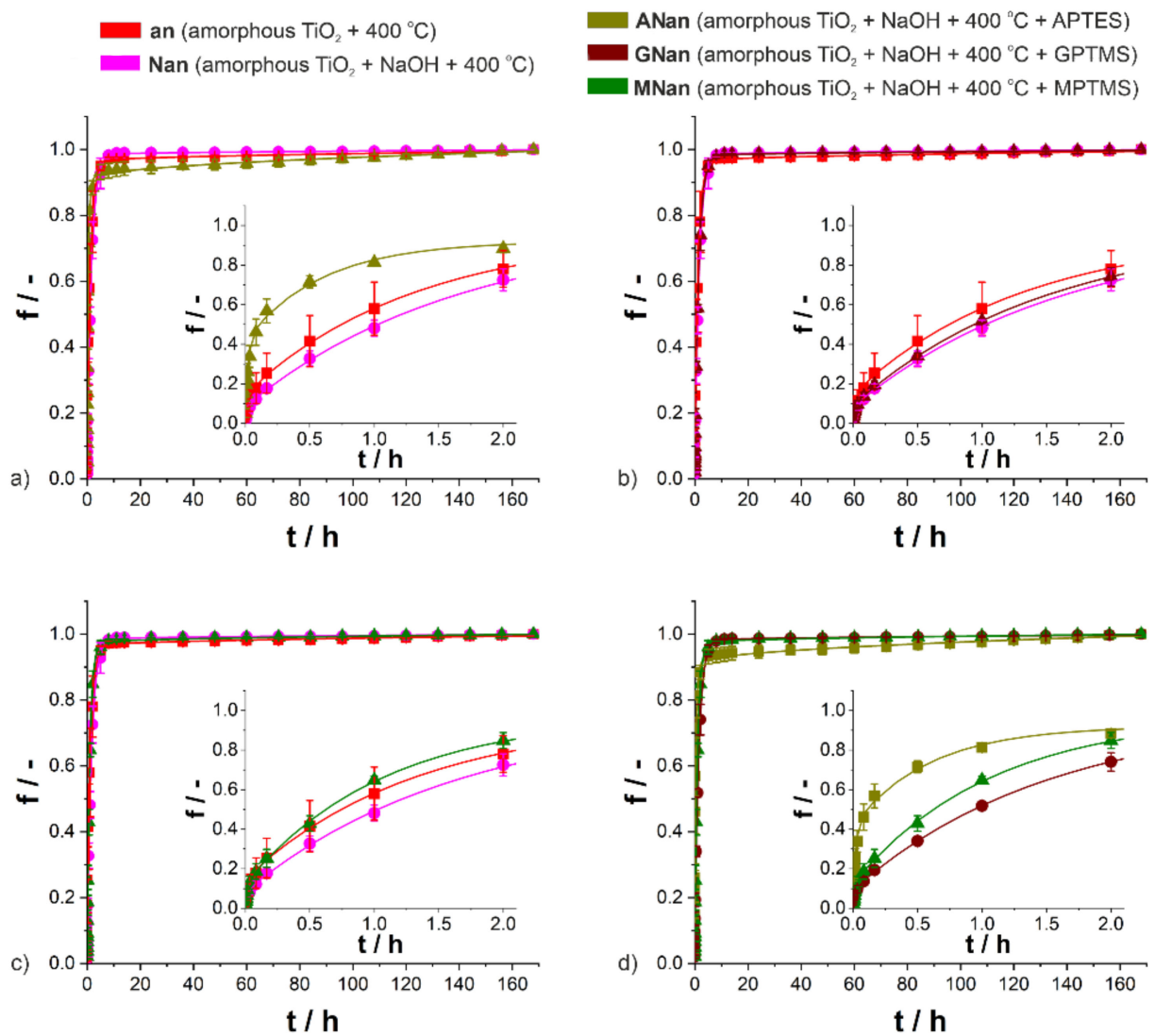

Figure 4. Drug release profiles of ibuprofen from the non-modified (an) and modified (Nan, Anan, GNan, and MNan) $\mathrm{TiO}_{2}$ samples with the fitted DDD model ((a) an, Nan, and Anan; (b) an, Nan, and GNan; (c) an, Nan, and MNan; (d) ANan, GNan, and MNan). Insets show the first $2 \mathrm{~h}$ of the release process (the standard deviations of the means, represented as bars, were calculated for $n=3$ ).

As expected, biphasic release behavior was observed for all types of systems (Figure 4). An initial burst release stage, which occurred immediately after the immersion in the PBS, was followed by slow ibuprofen delivery [25]. As shown in Table S3, the correlation coefficients were equal to 0.999 , which proved the accuracy of the DDD model fitting. In contrast to amorphous and functionalized ATO samples [11], no apparent effect of the surface functionalization on the ibuprofen release process and its kinetic parameters could be seen (Figure 4 and Table S3). As proved before [25], the presence of the anatase phase solely caused the significant reduction in the rate of ibuprofen delivery process, especially the decrease in the amount of drug released during the first stage. When modified with silane derivatives, only in the case of APTES were differences in the release kinetics observed, which may be correlated with a significantly lower amount of loaded ibuprofen for those samples $(0.9 \mathrm{mg})$ than for others $(1.9-3.0 \mathrm{mg})$ (Table S5). Based on the detailed analysis of kinetic parameters (Table S3), it can be stated that apart from the ANan samples, the parameters $\mathrm{f}_{1}$ and $\mathrm{k}_{1}$, which describe the first stage of the ibuprofen release process, take lower values for the modified and annealed $\mathrm{TiO}_{2}$ layers. For all samples, the parameter $f_{2}$ was above 0.910 , so it can be assumed that the drug release process was 
completed. The parameter $\mathrm{k}_{2}$ (i.e., the first-order kinetic constant for the second stage of the process) is ascribed to the kinetics of desorption from the inner surface of nanopores. The values for $\mathrm{NaOH}$-modified and GPTMS-modified samples were higher, while the values for APTES and MPTMS-modified samples were lower than those for only annealed titania. The reason for such behavior was the presence of $-\mathrm{NH}_{2}$ and $-\mathrm{SH}$ groups, which may slightly inhibit the process. Moreover, when the dissolution constant $\left(\mathrm{K}_{\mathrm{H}}\right)$ is considered, only modification with APTES can result in an increase in the diffusion of drug molecules inside nanopores. As shown in Table S5, for all five types of studied DDSs, the amount of drug released after a week is similar within the margin of error. Considering the above, although some differences may be observed, the functionalizations of annealed $\mathrm{TiO}_{2}$ layers with $\mathrm{NaOH}$ and silane derivatives (APTES, GPTMS, and MPTMS) have little or no effect on the ibuprofen delivery.

\subsection{Biocompatibility of the Modified ATO Layers}

We recently showed that the modification of amorphous $\mathrm{TiO}_{2}$ layers with $\mathrm{NaOH}$ and APTES improves the interaction between the samples and osteoblast-like cells line SAOS-2 [11]. In new studies, a cell line with a different phenotype (MG-63) has been chosen [47]. The MTS test, a one-step colorimetric method, was used to measure the cell metabolic activity after 2, 24, and $72 \mathrm{~h}$ incubations of MG-63 cells on the selected samples. The results are presented in Figure 5.

The MG-63 cells were incubated on the studied samples to analyze their adhesion, growth, and proliferation (Figure 5). After $2 \mathrm{~h}$ of cultivation, for all surfaces, the cells metabolic activity was in the range of $40-80 \%$ of the activity of control cells cultivated on PS (polystyrene) (Figure 5a), which means that the initial cell adhesion to the modified surfaces was less effective. While the presence of -OH groups at the surface has no impact on the activity of the cells, significant differences in their metabolism were observed for the anodic $\mathrm{TiO}_{2}$ layers modified with silane derivatives (Figure 5a). At this point, only adhesion of cells took place, so its slower rate may have caused the observed differences. After the $24 \mathrm{~h}$ incubation, the cell's activity reached the PS level, though the statistical significance was observed only for $\mathrm{NaOH}$ and GPTMS modifications (Figure 5b). The same tendency was noticed for the $72 \mathrm{~h}$ cultivation (Figure $5 \mathrm{c}$ ). Such behavior may be explained with regard to the wettability of the samples shown earlier, where the highest hydrophilicity was observed for those two types of modifications. It proves that wettability plays a crucial role in the adsorption of the molecules and in cell adhesion. Considering the above, it may be concluded that surface modification with GPTMS affects the adhesion and proliferation of MG-63 cells the most. Similar improvement in biocompatibility for such a change has also been observed for the L-929 fibroblasts cell line [48]. Therefore, it can be assumed that GPTMS-modified ATO layers will be promising in terms of using titanium-based implants.

The immunofluorescence images and FE-SEM images of MG-63 cells after $24 \mathrm{~h}$ of incubation showing the morphology of adhered cells are presented in Figure 6; those after 2 and $72 \mathrm{~h}$ are shown in Figure S8. After $24 \mathrm{~h}$ (Figure 6), the cells were well spread on all samples with clearly marked actin filaments. This is also supported by the FE-SEM images, where well-flattened cells with clearly visible filopodia may be seen (Figure $6 \mathrm{~b}, \mathrm{~d}, \mathrm{f}, \mathrm{h}, \mathrm{j}$ ), which indicates good cell adhesion due to the presence of appropriate adhesive sites [49]. The same observations were reported by Lin et al. [17] for 3T3 fibroblasts on anodic non-modified and silane derivative-modified $\mathrm{TiO}_{2}$ layers. No significant differences in the morphology of the MG-63 cells were observed, proving the biocompatibility of the proposed modified ATO layers. 

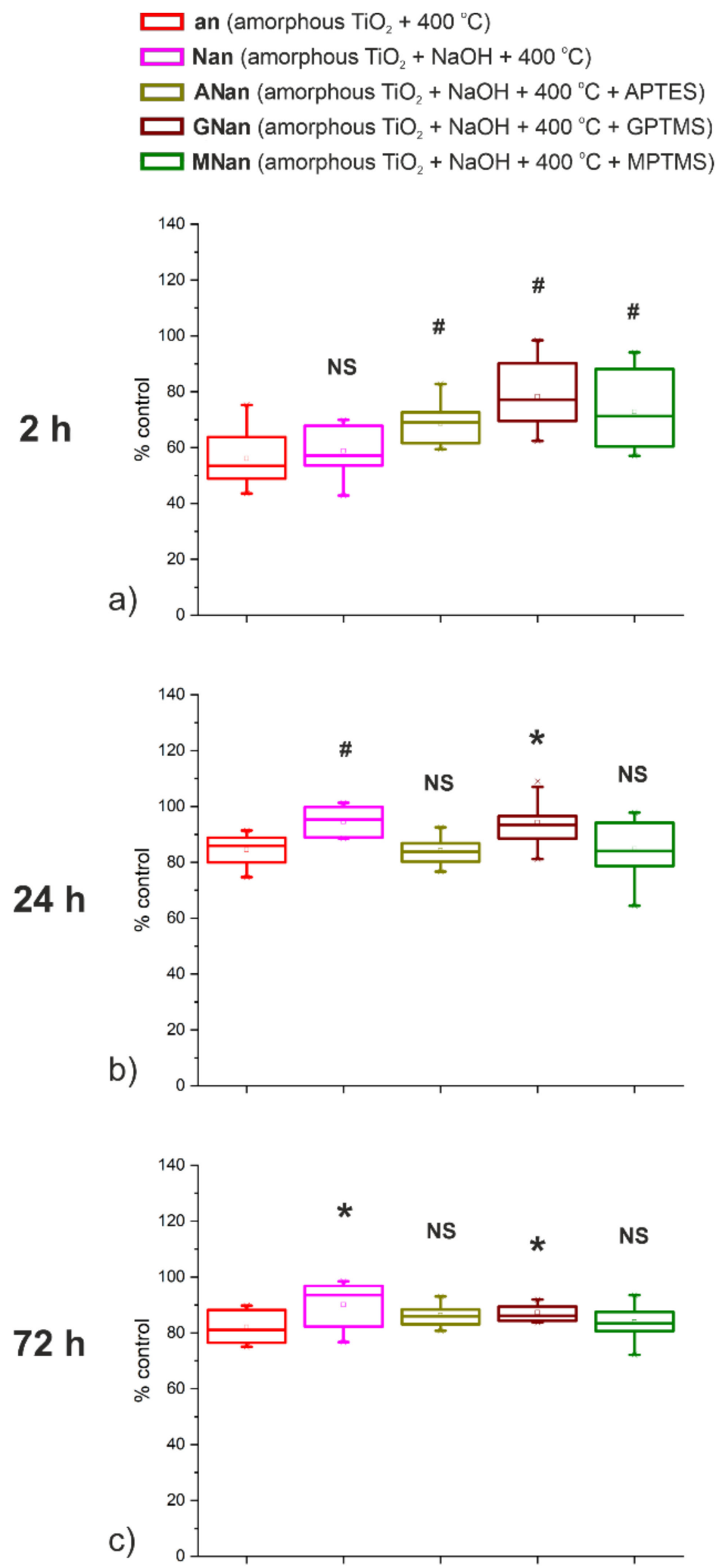

Figure 5. Metabolic activity of osteoblast-like cell line MG-63 incubated on the non-modified (an) and modified (Nan, Anan, GNan, and MNan) $\mathrm{TiO}_{2}$ samples after 2 (a), 24 (b), and 72 (c) hours. The values are expressed as percentages of the positive control (PS); NS-not statistically significant differences, * - statistically significant differences at the alpha level of 0.05 , \#-statistically significant differences at the alpha level of 0.01 , based on ANOVA. 


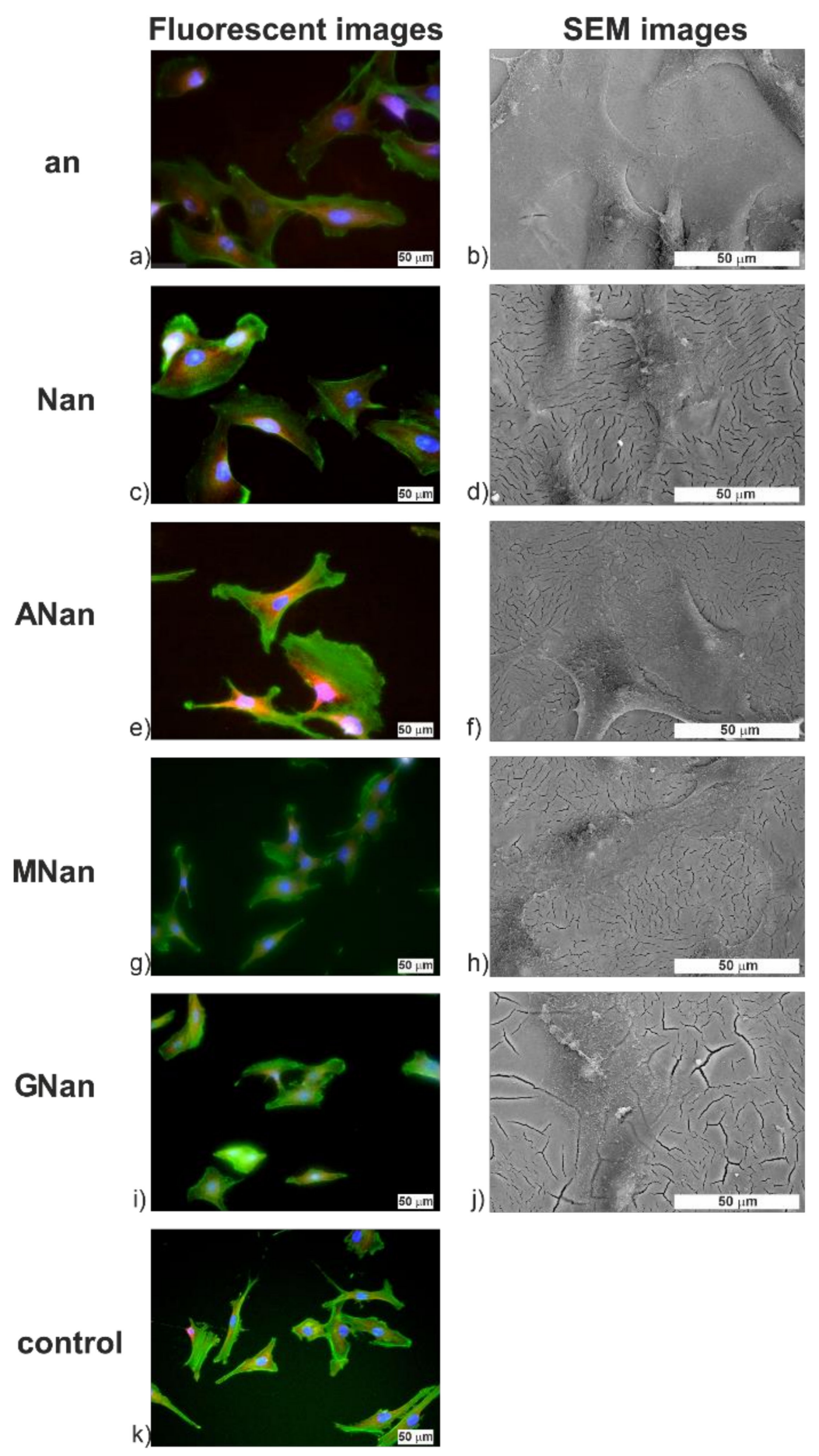

Figure 6. Representative immunofluorescence and FE-SEM microphotographs of MG-63 osteoblastlike cells grown on the non-modified (an) (a,b) and modified (Nan, Anan, GNan, and MNan) (c-j) $\mathrm{TiO}_{2}$ samples, and the control (polystyrene) (k) after $24 \mathrm{~h}$ of culture. For fluorescent microscopy imaging, cells were stained with actin skeleton (green), cell nuclei (blue), and vinculin (red). Scale bar $=50 \mu \mathrm{m}$.

To sum up, it may be stated that all of the proposed samples are biocompatible and facilitate the adhesion and proliferation of osteoblast-like cells. However, the most significant changes after 24 and $72 \mathrm{~h}$ of incubation may be observed only for the samples modified with $\mathrm{NaOH}$ and GPTMS, proving that surface groups (i.e., - $\mathrm{OH}$ and glycidyl) play essential roles in the interactions between the material and cells. 


\section{Materials and Methods}

\subsection{Synthesis of Nanostructured Titanium Dioxide on Ti Substrate}

Rectangular Ti samples with dimensions of $1 \mathrm{~cm} \times 2 \mathrm{~cm}$ were first degreased in acetone and ethanol, and then polished electrochemically (in the mixture of acetic, sulfuric, and hydrofluoric acids) and chemically (in the mixture of hydrofluoric and nitric acids) [50]. After being rinsed with distilled water and ethanol, the Ti samples were dried in the air. Nanoporous $\mathrm{TiO}_{2}$ layers were prepared via a three-step anodization process in a two-electrode cell with titanium foils as both the anode and cathode. Details regarding the standard anodization parameters applied in this work may be found in our previous papers [51-53]. As a result, the $\mathrm{TiO}_{2}$ films with a suitable pore arrangement were synthesized.

\subsection{Modification of Surface and Crystalline Structure of $\mathrm{TiO}_{2}$ Layers}

Two approaches were used to examine how the crystalline structure of $\mathrm{TiO}_{2}$ affects the surface modification of ATO layers with sodium hydroxide. Firstly, the samples were annealed at the temperature of 400 or $600{ }^{\circ} \mathrm{C}$ for $2 \mathrm{~h}$ in a muffle furnace (model FCF5-SHM Z, Czylok, Jastrzębie-Zdrój, Poland) to obtain the anatase and a mixture of anatase and rutile phases, respectively. After the heat treatment, the $\mathrm{TiO}_{2}$ layers were immersed in $\mathrm{NaOH}(0.5$ or $1.0 \mathrm{M})$ for $15 \mathrm{~min}$ and rinsed with distilled water. In the second approach, $\mathrm{TiO}_{2}$ layers were first immersed in sodium hydroxide and then annealed. The morphology of samples was examined by field emission scanning electron microscopy with energydispersive X-ray spectroscopy (FE-SEM/EDS, Hitachi S-4700 with a Noran System 7, Krefeld, Germany).

Subsequent surface changes with silane derivatives (APTES, GPTMS, and MPTMS) were achieved by immersing the $\mathrm{NaOH}$-modified and annealed samples in a $1 \%$ ethanolic solution silane derivatives for $2 \mathrm{~h}$ and rinsing with absolute ethanol. The characterization of the modified nanostructured $\mathrm{TiO}_{2}$ was performed using $\mathrm{X}$-ray photoelectron spectroscopy (ESCA/XPS) with an Al X-ray source (1486.7 eV) and a semi-spherical analyzer SES R4000 (Gammadata Scienta, Uppsala, Sweden). The maximum energy resolution for the $\mathrm{Ag} 3 \mathrm{~d}_{5 / 2}$ line was $1.0 \mathrm{eV}$ (for analyzer pass energy of $100 \mathrm{eV}$ ). The curves were fitted with a Voigt profile $(\mathrm{GL}=30)$ and a Shirley background using CasaXPS software 2.3.15.

The contact angle was measured using a sessile drop technique (goniometer DataPhysics OCA25 equipped with a CCD device and computer, Filderstadt, Germany) to determine the effect of the surface modification on the wettability of $\mathrm{TiO}_{2}$ layers. The contact angle was measured 10 times for each deionized water droplet. The procedure was repeated three times for each type of sample.

\subsection{Ibuprofen Delivery Process}

An ibuprofen release process from anodic $\mathrm{TiO}_{2}$ layers was examined for selected samples. A standardized loading strategy described previously was applied [25,26]. Briefly, $1 \mathrm{~mL}$ of a $10 \mathrm{wt} . \%$ solution of ibuprofen in ethanol (Polfarmex-Kutno, Kutno, Poland) was pipetted fivefold onto the anodic $\mathrm{TiO}_{2}$ layers, followed by air drying at room temperature. Afterward, the ibuprofen excess was removed from the surface with the paper towel, and samples were weighed after a $24 \mathrm{~h}$-storage in a desiccator.

In vitro drug delivery was carried out for a week according to the optimized procedure $[25,26]$. The drug-loaded sample was immersed in the $0.01 \mathrm{M}$ phosphate buffer solution (PBS, $\mathrm{pH}=7.4)$ at a temperature of $37 \pm 1{ }^{\circ} \mathrm{C}$. The whole volume of PBS $(6 \mathrm{~mL})$ was replaced with a fresh portion of the solution at predetermined time points. The ibuprofen concentration was determined based on the UV-Vis spectra recorded at the wavelength range of 190-300 nm (Thermo Scientific Evolution 220 coupled with Thermo Scientific Insight software, Waltham, MA, USA) and then calculated based on the absorbance measurements at $222 \mathrm{~nm}$ and constructed calibration curve. The desorption-desorption-diffusion (DDD) model was fitted to the obtained data to determine the kinetics of the process. 


\subsection{Cell Cultivation on Studied ATO Layers}

The human osteoblast-like cell line MG-63 (ATCC®CRL-1427, LGS Standards, UK) was cultivated in DMEM (Dulbecco's modified eagle's medium) with glucose, phenol red, and L-glutamine (Sigma-Aldrich, St. Louis, MI, USA) supplemented with $10 \%$ heatinactivated fetal bovine serum (FBS) (HyClone, Logan, UT, USA), penicillin (10 $\mathrm{U} \mathrm{mL}^{-1}$, HyClone), and streptomycin $\left(10 \mu \mathrm{g} \mathrm{mL}{ }^{-1}\right.$, HyClone) $)$ at $37^{\circ} \mathrm{C}$ in a $5 \% \mathrm{CO}_{2}$ atmosphere. The biological experiments were performed for five types of samples: an, Nan, Anan, GNan, and MNan. Firstly, the samples were exposed to UV light for $15 \mathrm{~min}$ in order to sterilize them. The cells were seeded on ATO layers in 24-well tissue culture plates, and tissue culture polystyrene (PS) was used as a control. In the biological studies, a seeding density of 10,000 cells cm ${ }^{-2}$ was used. The seeded MG-63 cells were incubated for 2, 24, and $72 \mathrm{~h}$.

\subsection{Examination of the Metabolic Activity and Morphology of MG-63 Cells}

The CellTiter $96^{\circledR}$ Aqueous One Solution Cell Proliferation Assay (MTS, Promega, Madison, WI, USA) was applied to determine the number of viable cells. After 2, 24, or $72 \mathrm{~h}$, the medium was removed, and a $10 \%$ MTS solution in the DMEM medium was added. After the next 2 -h incubation at $37{ }^{\circ} \mathrm{C}, 100 \mu \mathrm{L}$ of $10 \%$ MTS solution in DMEM was transferred into a 96-well plate (in triplicates for each sample). In the end, the absorbance at $490 \mathrm{~nm}$ was measured with a multi-detection micro-plate reader $\left(\mathrm{Epoch}^{\mathrm{TM}}\right.$ 2, BioTek, Winooski, VT, USA). The results were expressed as ratios of absorbance measured for the $\mathrm{TiO}_{2}$ samples to absorbance of the control (tissue culture PS). The statistical analysis was based on twelve results for each type of sample obtained from two independent experiments. The evaluation was carried out using one-way analysis of variance (ANOVA) (significance assessed at $p<0.05$ ) in R Studio software [54].

The cells were immunofluorescently labeled after the same incubation times to determine their morphology on the substrates, according to the previously shown procedure [11]. The cells were fixed in 4\% paraformaldehyde in PBS for $15 \mathrm{~min}$ and then rinsed with PBS. To increase the cell membranes' permeability, 0.1\% Triton X-100 (Sigma-Aldrich, Poland) in PBS was added to each well and incubated for $20 \mathrm{~min}$. After that, the cells were rinsed with PBS, and the blocking solution containing $1 \%$ FBS and $0.05 \%$ Tween ${ }^{\circledR} 20$ (Sigma-Aldrich, Poland) in PBS was added to block the non-specific binding sites. After a 30-min incubation, the solution was replaced with a primary antibody (mouse anti-vinculin monoclonal antibody) diluted in the blocking solution (1:500, Sigma-Aldrich), and incubated for $1 \mathrm{~h}$ at $37^{\circ} \mathrm{C}$. Next, the samples were rinsed with PBS. Afterward, secondary antibody, goat antimouse (1:500, Invitrogen, Carlsbad, CA, USA), and phalloidin-Alexa 488 (1:500, Invitrogen) in a blocking solution, were added and incubated at $37^{\circ} \mathrm{C}$ for $45 \mathrm{~min}$. After the rinse with PBS, the cell nuclei were labeled with 4',6-diamidino-2-phenylindole dihydrochloride in PBS (DAPI, 1:1000, Sigma-Aldrich, Poland) and incubated for $15 \mathrm{~min}$. In the end, the ATO layers were rinsed with PBS and mounted with a mounting medium (Thermo Scientific ${ }^{\mathrm{TM}}$ Shandon ${ }^{\mathrm{TM}}$ Immu-Mount ${ }^{\mathrm{TM}}$, Thermo Scientific). Fluorescence images of the stained MG-63 cells were obtained with the Olympus IX51 (Olympus, Warsaw, Poland) equipped with an XC10 camera.

Additionally, the morphology of the studied samples was examined by using the scanning electron microscope. ATO layers were firstly fixed with a $3 \%$ glutaraldehyde solution for $24 \mathrm{~h}$. The samples were then rinsed three times with PBS and dehydrated in the alcohol series (the ethanol solutions with a concentration of $50 \%, 60 \%, 70 \%, 80 \%, 90 \%$, $96 \%$, and $100 \%$ ). Non-modified and modified $\mathrm{TiO}_{2}$ were placed in each solution for $15 \mathrm{~min}$. Finally, the substrates were dried for $1 \mathrm{~min}$ in the solution of hexamethyldisilazane [55]. Before the samples were characterized with SEM, they were coated with a 15-nm layer of gold using a sputter coater (Quorum Q150T S, UK). 


\section{Conclusions}

This report has shown how structural and surface modifications of nanostructured $\mathrm{TiO}_{2}$ influence the biocompatibility and drug release properties.

It was found that anatase and mixed anatase and rutile phases could not be effectively modified with $\mathrm{NaOH}$, whereas a crystalline structure change is possible for the $\mathrm{NaOH}$ modified samples. Therefore, for effective and nondestructive modification, the sequence of the modification steps is crucial. Moreover, such samples may be further functionalized with silane derivatives having different functional groups. Both the heat treatment and surface functionalization improved the hydrophilicity of the studied ATO surfaces, which are crucial for biomedical applications.

Modified ATO layers were used to test the ibuprofen release from the nanopores. Unfortunately, the additional modifiers did not affect the release kinetics in any way. The most significant improvement was observed only for the annealed layers. On the other hand, the proposed modifications improved the cell responses on the studied substrates. The biological studies showed an increase in the metabolic activity of MG-63 cells and improvement in the cells' morphology, especially when samples were modified with APTES and GPTMS.

To summarize, the presented data provide more information about the surface modification of nanostructured anatase layers. It can also be postulated that the modifications with APTES and GPTMS were the most beneficial for the potential implantable materials, which improve cell response and provide drug molecules directly at the implantation site.

Supplementary Materials: Figure S1: EDS spectra of nanoporous $\mathrm{TiO} 2$ layers annealed at $400{ }^{\circ} \mathrm{C}$ for $2 \mathrm{~h}$ and then immersed in $0.5 \mathrm{M}$ (a) or $1.0 \mathrm{M} \mathrm{(b)} \mathrm{NaOH}$ for $15 \mathrm{~min}$. The Au peak in the spectra has arisen from a gold layer sputtered before SEM examination. Table S1: Elemental compositions (Ti, $\mathrm{O}, \mathrm{Na}$, and $\mathrm{F}$ ) of $\mathrm{TiO} 2$ samples annealed at $400{ }^{\circ} \mathrm{C}$ for $2 \mathrm{~h}$ and then immersed in 0.5 or $1.0 \mathrm{M}$ $\mathrm{NaOH}$ for $15 \mathrm{~min}$, calculated based on EDS spectra. Figure S2: EDS spectra of nanoporous $\mathrm{TiO} 2$ layers modified with $0.5 \mathrm{M}$ (a) or $1.0 \mathrm{M}$ (b) NaOH for $15 \mathrm{~min}$ and then annealed at $400{ }^{\circ} \mathrm{C}$ for $2 \mathrm{~h}$. The Au peak in the spectra has arisen from a gold layer sputtered before SEM examination. Table S2: Elemental composition ( $\mathrm{Ti}, \mathrm{O}, \mathrm{Na}$, and F) of $\mathrm{TiO} 2$ samples modified with $0.5 \mathrm{M}$ or $1.0 \mathrm{M} \mathrm{NaOH}$ for $15 \mathrm{~min}$ and then annealed at $400{ }^{\circ} \mathrm{C}$ for $2 \mathrm{~h}$, calculated based on EDS spectra. Figure S3: Core-level XPS spectra of N 1s for the ANan sample. Figure S4: Core-level XPS spectra of S $2 p$ for the MNan sample. Figure S5: Core-level XPS spectra of Si 2p for the ANan (a), GNan (b), and MNan (c) samples. Figure S6: Core-level XPS spectra of O 1s for the an (a), Nan (b), ANan (c), GNan (d), and MNan (e) samples. Figure S7: Core-level XPS spectra of C 1s for the an (a), Nan (b), ANan (c), GNan (d), and MNan (e) samples. Table S3: The desorption-desorption-diffusion model parameters $\left(\mathrm{f}_{1}, \mathrm{f}_{2}, \mathrm{k}_{1}, \mathrm{k}_{2}\right.$, $\mathrm{K}_{\mathrm{H}}$ ) with parameter standard errors for the ibuprofen release from the modified and non-modified annealed TiO2 layers. Table S4: The amounts of ibuprofen released after pre-determined time points, namely, $10 \mathrm{~s}, 60 \mathrm{~s}, 10 \mathrm{~min}, 30 \mathrm{~min}, 1 \mathrm{~h}, 2 \mathrm{~h}, 24 \mathrm{~h}$, and $168 \mathrm{~h}$, from the modified and non-modified annealed TiO2 layers. Table S5: The amounts of ibuprofen loaded inside nanoporous $\mathrm{TiO} 2$ layers and released after $168 \mathrm{~h}$ from the modified and non-modified annealed $\mathrm{TiO} 2$ samples (with standard deviation, $n=3)$. Figure S8: Representative immunofluorescence images of MG-63 osteoblast-like cells grown on the an (anatase $\mathrm{TiO} 2)(\mathrm{a}, \mathrm{b})$, Nan (amorphous $\left.\mathrm{TiO} 2+\mathrm{NaOH}+400{ }^{\circ} \mathrm{C}\right)(\mathrm{c}, \mathrm{d}), \mathrm{ANan}$ (amorphous $\left.\mathrm{TiO} 2+\mathrm{NaOH}+400{ }^{\circ} \mathrm{C}+\mathrm{APTES}\right)(\mathrm{e}, \mathrm{f}), \mathrm{GNan}$ (amorphous $\mathrm{TiO} 2+\mathrm{NaOH}+400{ }^{\circ} \mathrm{C}+$ GPTMS) (g,h), MNan (amorphous $\left.\mathrm{TiO} 2+\mathrm{NaOH}+400{ }^{\circ} \mathrm{C}+\mathrm{MPTMS}\right)(\mathrm{i}, \mathrm{j})$, and control (polystyrene) $(\mathrm{k}, \mathrm{l})$ samples after 2 and $72 \mathrm{~h}$ of culture. Cells were stained with actin skeleton (green), cell nuclei (blue), and vinculin (red). Scale bar $=50 \mu \mathrm{m}$.

Author Contributions: A.P., M.J., and G.D.S. designed the experiments; A.P., M.J., and R.P.S. performed the experiments; A.P., M.J., R.P.S., and G.D.S. analyzed the data; A.P. prepared the figures and tables. The manuscript was written through contributions from all of the authors. All authors have read and agreed to the published version of the manuscript.

Funding: This research was financially supported by the National Science Centre, Poland (grant number 2016/21/N/ST5/00872 and 2018/28/T/ST5/00413).

Institutional Review Board Statement: Not applicable. 
Informed Consent Statement: Not applicable.

Data Availability Statement: Data sharing not applicable.

Acknowledgments: The SEM imaging was performed in the Laboratory of Field Emission Scanning Electron Microscopy and Microanalysis at the Institute of Geological Sciences, Jagiellonian University, Poland. The authors would like to thank Joanna Lewandowska-Łańcucka for providing the MG-63 cell line, Olga Mazuryk for the access to the fluorescence microscope, and Kamil Kamiński for to access to the biology laboratory.

Conflicts of Interest: The authors declare no conflict of interest.

Sample Availability: Not available.

\section{References}

1. Awad, N.K.; Edwards, S.L.; Morsi, Y.S. A review of $\mathrm{TiO}_{2}$ NTs on Ti metal: Electrochemical synthesis, functionalization and potential use as bone implants. Mater. Sci. Eng. C 2017, 76, 1401-1412. [CrossRef] [PubMed]

2. Tranquilli Leali, P.; Merolli, A. Fundamentals of Biomaterials. In Biomaterials in Hand Surgery; Merolli, A., Joyce, T.J., Eds.; Springer: Berlin/Heidelberg, Germany, 2009; pp. 1-11.

3. Frandsen, C.J.; Noh, K.; Brammer, K.S.; Johnston, G.; Jin, S. Hybrid micro/nano-topography of a $\mathrm{TiO}_{2}$ nanotube-coated commercial zirconia femoral knee implant promotes bone cell adhesion in vitro. Mater. Sci. Eng. C 2013, 33, 2752-2756. [CrossRef] [PubMed]

4. Minagar, S.; Wang, J.; Berndt, C.C.; Ivanova, E.P.; Wen, C. Cell response of anodized nanotubes on titanium and titanium alloys. J. Biomed. Mater. Res. Part. A 2013, 101 A, 2726-2739. [CrossRef]

5. Salata, O.V. Applications of nanoparticles in biology and medicine. J. Nanobiotechnol. 2004, 6, 1-6. [CrossRef]

6. Baldwin, F.; Craig, T.J.; Shiel, A.I.; Cox, T.; Lee, K.; Mansell, J.P. Polydopamine-lysophosphatidate-functionalised titanium: A novel hybrid surface finish for bone regenerative applications. Molecules 2020, 25, 1583. [CrossRef]

7. Kim, S.Y.; Kim, Y.K.; Park, I.S.; Jin, G.C.; Bae, T.S.; Lee, M.H. Effect of alkali and heat treatments for bioactivity of TiO ${ }_{2}$ nanotubes. Appl. Surf. Sci. 2014, 321, 412-419. [CrossRef]

8. Oh, S.H.; Finõnes, R.R.; Daraio, C.; Chen, L.H.; Jin, S. Growth of nano-scale hydroxyapatite using chemically treated titanium oxide nanotubes. Biomaterials 2005, 26, 4938-4943. [CrossRef] [PubMed]

9. Oh, S.; Jin, S. Titanium oxide nanotubes with controlled morphology for enhanced bone growth. Mater. Sci. Eng. C 2006, 26, 1301-1306. [CrossRef]

10. Yao, C.; Webster, T.J. Prolonged antibiotic delivery from anodized nanotubular titanium using a co-precipitation drug loading method. J. Biomed. Mater. Res. Part. B Appl. Biomater. 2009, 91, 587-595. [CrossRef]

11. Pawlik, A.; Socha, R.P.; Hubalek Kalbacova, M.; Sulka, G.D. Surface modification of nanoporous anodic titanium dioxide layers for drug delivery systems and enhanced SAOS-2 cell response. Colloids Surf. B Biointerfaces 2018, 171, 58-66. [CrossRef] [PubMed]

12. Anselme, K.; Ploux, L.; Ponche, A. Cell/material interfaces: Influence of surface chemistry and surface topography on cell adhesion. J. Adhes. Sci. Technol. 2010, 24, 831-852. [CrossRef]

13. Mani, G.; Johnson, D.M.; Marton, D.; Dougherty, V.L.; Feldman, M.D.; Patel, D.; Ayon, A.A.; Mauli Agrawal, C. Stability of self-assembled monolayers on titanium and gold. Langmuir 2008, 24, 6774-6784. [CrossRef] [PubMed]

14. Brnardić, I.; Huskić, M.; Umek, P.; Grgurić, T.H. Sol-gel functionalization of sodium $\mathrm{TiO}_{2}$ nanotubes and nanoribbons with aminosilane molecules. Ceram. Int. 2013, 39, 9459-9464. [CrossRef]

15. Huskić, M.; Grgurić, T.H.; Umek, P.; Brnardić, I. Functionalization of sodium titanate nanoribbons with silanes and their use in the reinforcement of epoxy nanocomposites. Polym. Compos. 2013, 34, 1382-1388. [CrossRef]

16. Mandal, S.S.; Jose, D.; Bhattacharyya, A.J. Role of surface chemistry in modulating drug release kinetics in titania nanotubes. Mater. Chem. Phys. 2014, 147, 247-253. [CrossRef]

17. Lin, S.P.; Huang, S.Y.; Chen, S.F.; Vinzons, L.U.; Ciou, J.Y.; Wong, P.J. Investigation of the interfacial effects of small chemicalmodified $\mathrm{TiO}_{2}$ nanotubes on $3 \mathrm{~T} 3$ fibroblast responses. ACS Appl. Mater. Interfaces 2014, 6, 12071-12082. [CrossRef]

18. Paz, Y. Self-assembled monolayers and titanium dioxide: From surface patterning to potential applications. Beilstein J. Nanotechnol. 2011, 2, 845-861. [CrossRef]

19. Kulkarni, M.; Mazare, A.; Gongadze, E.; Perutkova, S.; Kralj-Iglic, V.; Milošev, I.; Schmuki, P.; Iglič, A.; Mozetič, M. Titanium nanostructures for biomedical applications. Nanotechnology 2015, 26, 062002. [CrossRef] [PubMed]

20. Jarosz, M.; Syrek, K.; Kapusta-Kołodziej, J.; Mech, J.; Małek, K.; Hnida, K.; Łojewski, T.; Jaskuła, M.; Sulka, G.D. Heat treatment effect on crystalline structure and photoelectrochemical properties of anodic $\mathrm{TiO}_{2}$ nanotube arrays formed in ethylene glycol and glycerol based electrolytes. J. Phys. Chem. C 2015, 119, 24182-24191. [CrossRef]

21. Sreekantan, S.; Saharudin, K.A.; Wei, L.C. Formation of $\mathrm{TiO}_{2}$ nanotubes via anodization and potential applications for photocatalysts, biomedical materials, and photoelectrochemical cell. IOP Conf. Ser. Mater. Sci. Eng. 2011, 21, 012002. [CrossRef] 
22. Cipriano, A.F.; Miller, C.; Liu, H. Anodic growth and biomedical applications of $\mathrm{TiO}_{2}$ nanotubes. J. Biomed. Nanotechnol. 2014, 10, 2977-3003. [CrossRef]

23. Ercan, B.; Taylor, E.; Alpaslan, E.; Webster, T.J. Diameter of titanium nanotubes influences anti-bacterial efficacy. Nanotechnology 2011, 22, 295102. [CrossRef] [PubMed]

24. Li, H.; Cui, Q.; Feng, B.; Wang, J.; Lu, X.; Weng, J. Antibacterial activity of $\mathrm{TiO}_{2}$ nanotubes: Influence of crystal phase, morphology and Ag deposition. Appl. Surf. Sci. 2013, 284, 179-183. [CrossRef]

25. Jarosz, M.; Pawlik, A.; Szuwarzyński, M.; Jaskuła, M.; Sulka, G.D. Nanoporous anodic titanium dioxide layers as potential drug delivery systems: Drug release kinetics and mechanism. Colloids Surf. B Biointerfaces 2016, 143, 447-454. [CrossRef] [PubMed]

26. Pawlik, A.; Jarosz, M.; Syrek, K.; Sulka, G.D. Co-delivery of ibuprofen and gentamicin from nanoporous anodic titanium dioxide layers. Colloids Surf. B Biointerfaces 2017, 152, 95-102. [CrossRef]

27. Popat, K.C.; Eltgroth, M.; LaTempa, T.J.; Grimes, C.A.; Desai, T.A. Titania nanotubes: A novel platform for drug-eluting coatings for medical implants? Small 2007, 3, 1878-1881. [CrossRef] [PubMed]

28. Doadrio, A.L.; Sánchez-Montero, J.M.; Doadrio, J.C.; Salinas, A.J.; Vallet-Regí, M. A molecular model to explain the controlled release from SBA-15 functionalized with APTES. Microporous Mesoporous Mater. 2014, 195, 43-49. [CrossRef]

29. Doadrio, A.L.; Conde, A.; Arenas, M.A.; Hernández-López, J.M.; De Damborenea, J.J.; Pérez-Jorge, C.; Esteban, J.; Vallet-Regí, M. Use of anodized titanium alloy as drug carrier: Ibuprofen as model of drug releasing. Int. J. Pharm. 2015, 492, 207-212. [CrossRef]

30. Brammer, K.S.; Frandsen, C.J.; Jin, S. $\mathrm{TiO}_{2}$ nanotubes for bone regeneration. Trends Biotechnol. 2012, 30, 315-322. [CrossRef] [PubMed]

31. Li, M.; Mondrinos, M.J.; Chen, X.; Gandhi, M.R.; Ko, F.K.; Lelkes, P.I. Elastin Blends for Tissue Engineering Scaffolds. J. Biomed. Mater. Res. Part. A 2006, 79, 963-973. [CrossRef]

32. Czekanska, E.M.; Stoddart, M.J.; Richards, R.G.; Hayes, J.S. In search of an osteoblast cell model for in vitro research. Eur. Cells Mater. 2012, 24, 1-17. [CrossRef]

33. Lai, M.; Jin, Z.; Su, Z. Surface modification of $\mathrm{TiO}_{2}$ nanotubes with osteogenic growth peptide to enhance osteoblast differentiation. Mater. Sci. Eng. C 2017, 73, 490-497. [CrossRef] [PubMed]

34. Lai, M.; Jin, Z.; Qiao, W. Surface immobilization of gelatin onto $\mathrm{TiO}_{2}$ nanotubes to modulate osteoblast behavior. Colloids Surf. $B$ Biointerfaces 2017, 159, 743-749. [CrossRef] [PubMed]

35. Kulkarni, M.; Patil-Sen, Y.; Junkar, I.; Kulkarni, C.V.; Lorenzetti, M.; Iglič, A. Wettability studies of topologically distinct titanium surfaces. Colloids Surf. B Biointerfaces 2015, 129, 47-53. [CrossRef] [PubMed]

36. Gongadze, E.; Kabaso, D.; Bauer, S.; Slivnik, T.; Schmuki, P.; van Rienen, U.; Iglič, A. Adhesion of osteoblasts to a nanorough titanium implant surface. Int. J. Nanomed. 2011, 6, 1801-1816.

37. Yang, T.; Qian, S.; Qiao, Y.; Liu, X. Cytocompatibility and antibacterial activity of titania nanotubes incorporated with gold nanoparticles. Colloids Surf. B Biointerfaces 2016, 145, 597-606. [CrossRef] [PubMed]

38. Brammer, K.S.; Oh, S.; Cobb, C.J.; Bjursten, L.M.; van der Heyde, H.; Jin, S. Improved bone-forming functionality on diametercontrolled $\mathrm{TiO}_{2}$ nanotube surface. Acta Biomater. 2009, 5, 3215-3223. [CrossRef] [PubMed]

39. YazdanYar, A.; Aschauer, U.; Bowen, P. Interaction of biologically relevant ions and organic molecules with titanium oxide (rutile) surfaces: A review on molecular dynamics studies. Colloids Surf. B Biointerfaces 2018, 161, 563-577. [CrossRef]

40. He, J.; Zhou, W.; Zhou, X.; Zhong, X.; Zhang, X.; Wan, P.; Zhu, B.; Chen, W. The anatase phase of nanotopography titania plays an important role on osteoblast cell morphology and proliferation. J. Mater. Sci. Mater. Med. 2008, 19, 3465-3472. [CrossRef]

41. Kunze, J.; Müller, L.; Macak, J.M.; Greil, P.; Schmuki, P.; Müller, F.A. Time-dependent growth of biomimetic apatite on anodic $\mathrm{TiO}_{2}$ nanotubes. Electrochim. Acta 2008, 53, 6995-7003. [CrossRef]

42. Morgado, E.; De Abreu, M.A.S.; Moure, G.T.; Marinkovic, B.A.; Jardim, P.M.; Araujo, A.S. Characterization of nanostructured titanates obtained by alkali treatment of $\mathrm{TiO}_{2}$-anatases with distinct crystal sizes. Chem. Mater. 2007, 19, 665-676. [CrossRef]

43. Wang, Y.; Wen, C.; Hodgson, P.; Li, Y. Biocompatibility of $\mathrm{TiO}_{2}$ nanotubes with different topographies. J. Biomed. Mater. Res. Part. A 2014, 102, 743-751. [CrossRef]

44. Shin, D.H.; Shokuhfar, T. Wettability changes of $\mathrm{TiO}_{2}$ nanotube surfaces. Nanotechnology 2011, 22, 315704. [CrossRef] [PubMed]

45. Kao, L.; Chen, Y. Characterization, photoelectrochemical properties, and surface wettabilities of transparent porous $\mathrm{TiO}_{2}$ thin films. J. Photochem. Photobiol. A Chem. 2017, 340, 109-119. [CrossRef]

46. Hamlekhan, A.; Butt, A.; Patel, S.; Royhman, D.; Takoudis, C.; Sukotjo, C.; Yuan, J.; Jursich, G.; Mathew, M.T.; Hendrickson, W.; et al. Fabrication of Anti-Aging $\mathrm{TiO}_{2}$ Nanotubes on Biomedical Ti Alloys. PLoS ONE 2014, 9, e96213. [CrossRef]

47. Pautke, C.; Schieker, M.; Tischer, T.; Kolk, A.; Neth, P.; Mutschler, W.; Milz, S. Characterization of osteosarcoma cell lines MG-63, Saos-2 and U-2 OS in comparison to human osteoblasts. Anticancer Res. 2004, 24, 3743-3748. [PubMed]

48. Khoshnood, N.; Zamanian, A.; Massoudi, A. Effect of silane-coupling modification on bioactivity and in vitro properties of anodized titania nanotube arrays. Mater. Lett. 2016, 185, 374-378. [CrossRef]

49. Dalby, M.J. Cellular response to low adhesion nanotopographies. Int. J. Nanomed. 2007, 2, 373-381.

50. Jarosz, M.; Kapusta-Kołodziej, J.; Jaskuła, M.; Sulka, G.D. Effect of different polishing methods on anodic titanium dioxide formation. J. Nanomater. 2015, 2015, 295126. [CrossRef] 
51. Sulka, G.D.; Kapusta-Kołodziej, J.; Brzózka, A.; Jaskuła, M. Fabrication of nanoporous $\mathrm{TiO}_{2}$ by electrochemical anodization. Electrochim. Acta 2010, 55, 4359-4367. [CrossRef]

52. Jarosz, M.; Pawlik, A.; Kapusta-Kołodziej, J.; Jaskuła, M.; Sulka, G.D. Effect of the previous usage of electrolyte on growth of anodic titanium dioxide (ATO) in a glycerol-based electrolyte. Electrochim. Acta 2014, 136, 412-421. [CrossRef]

53. Kapusta-Kołodziej, J.; Tynkevych, O.; Pawlik, A.; Jarosz, M.; Mech, J.; Sulka, G.D. Electrochemical growth of porous titanium dioxide in a glycerol-based electrolyte at different temperatures. Electrochim. Acta 2014, 144, 127-135. [CrossRef]

54. R Studio Software. Available online: www.rstudio.com (accessed on 3 July 2018).

55. Chissoe, W.F.; Vezey, E.L.; Skvarla, J.J. Hexamethyldisilazane as a drying agent for pollen scanning electron microscopy. Biotech. Histochem. 1994, 69, 192-198. [CrossRef] 